\section{Autophagic processes increase during senescence in cultured sheep neurons and astrocytes}

\author{
Vittorio Farina, Gianluca Lepore, \\ Francesca Biagi, Marcella Carcupino, \\ Marco Zedda
}

Department of Veterinary Medicine, University of Sassari, Italy

\section{Abstract}

A possible response to aging is autophagy, a self-digestion process in which portions of cytoplasm are encapsulated by double-membrane-bound structures and delivered to lysosome for degradation. A previous work of our group showed that astrocytes under starving conditions are characterized by a higher upregulation of the marker of autophagy LC3 II than neurons. Aim of the present work was to evaluate LC3 II expression in an aging model consisting in fetal sheep neurons and astrocytes at 10, 20 and 30 days of culture. Such model has been validated by a remarkable activity of $\beta$-galactosidase, commonly used to reveal cell aging. LC3 II immunoreactivity in neurons and astrocytes progressively increased with time but differences were observed on the basis of cell density. Indeed, LC3 II immunoreactivity is higher in clusters of neurons and astrocytes and this may be due to the fact that cell-cell contact would represent a second stress in addition to aging itself. Both cell types displayed a reduction in LC3 II signal in nuclei, and a corresponding strengthening in the cytoplasm with time. This may be due to the need of aged cells to remove damaged cytoplasmic components through autophagic processes. Such variation in LC3 II localization could be caused by migration from the nucleus to cytoplasm as well as possible de novo intracytoplasmic production. The present work based on sheep neural cells in vitro may represent a helpful tool in the studies on aging processes in which autophagy plays a remarkable role.

\section{Introduction}

During brain aging, neurons and astrocytes undergo biological, morphological, and functional changes. Damages induced by aging lead to deterioration of cell components and alteration in tissue homeostasis that finally compromise the whole organism. Thus, aging consists in a natural decline in organism homeostasis over time, ${ }^{1}$ presumably as the result of accumulative and unrepaired damages. During brain aging, increased oxidative stress and accumulation of damaged molecules promote dysfunction of different metabolic and signaling pathways. ${ }^{2}$ The aging process is associated with an increase in cellular stress and the induction of stress response pathways. ${ }^{3}$

Oxidative damage plays a pivotal role in the decline of brain functions, which could be explained by the increase in lipid peroxidation, ${ }^{4}$ protein oxidation ${ }^{5}$ and oxidative modifications of genomic and mitochondrial DNA. ${ }^{6}$ Reactive oxygen species (ROS) produced by oxidative process together with many other DNAdamaging agents can induce neural cells to enter a state of irreversible cell-cycle arrest, referred to as senescence. ${ }^{7,8}$

The central nervous system is particularly exposed to oxidative injuries because of the high rate of oxygen consumption, the large amount of easily peroxidizable fatty acids, and the relatively poor concentration of antioxidant defense systems. ${ }^{9,10}$ Senescent neural cells become enlarged and express a $\mathrm{pH}$-dependent $\beta$ galactosidase activity ${ }^{11}$ and the corresponding assay has become one of the most commonly used markers to detect cell aging. In a previous work carried out at our labs in sheep primary neurons exposed to the oxidant 3-nitro-L-tyrosine, an increase in $\beta$ galactosidase activity was observed with time, and a downregulation of $\beta$ II topoisomerase expression has been detected as a reaction to nitrosative stress. ${ }^{12}$ Indeed, $\beta$ II topoisomerase plays a role in DNA repair process in non-proliferating cells like neurons and its expression tends to be downregulated with senescence. ${ }^{13}$

One of the most important responses to stress conditions is autophagy, that could be referred as an extreme attempt to cell rescue. Autophagy is a self-digestion process by which cytoplasmic components are engulfed by double-membrane-bound structures (autophagosomes) and delivered to lysosome for degradation. ${ }^{14}$ During starvation and stress conditions, autophagic processes are often activated. ${ }^{15}$ The molecular mechanisms of autophagy have been well studied in Saccharomyces cerevisiae by investigations of proteins encoded by a group of genes that regulate autophagy, which are genetically conserved in all eukaryotes. ${ }^{16}$ Recently, the specific functional role of microtubuleassociated protein light chain 3 (MAP LC3) molecule was better clarified and two forms were identified. In details, during autophagic processes the form I of MAP LC3, named
Correspondence: Dr. Gianluca Lepore, Department of Veterinary Medicine, University of Sassari, Via Vienna 2, 07100 Sassari, Italy.

Tel. +39.079.229593 - Fax: +39.079.229432.

E-mail: lepore@uniss.it

Key words: Aging; neurons and astrocytes in vitro; autophagy; LC3 II; sheep.

Contributions: VF, designed the project; FB, designed the project and performed the experimental procedures; GL, MZ, performed the statistical analyses and wrote the paper; MC, performed the table and figures.

Conflict of interest: The Authors declare no conflict of interest.

Received for publication: 5 January 2018.

Accepted for publication: 21 February 2018

This work is licensed under a Creative Commons Attribution-NonCommercial 4.0 International License (CC BY-NC 4.0).

(C) Copyright V. Farina et al., 2018

Licensee PAGEPress, Italy

European Journal of Histochemistry 2018; 62:2891 doi:10.4081/ejh.2018.2891

LC3 I, is covalently linked to phosphatidylethanolamine (PE) and is incorporated into autophagosome membranes, where it recruits cargo. This mechanism is mediated by $\operatorname{Atg} 3$ and $\operatorname{Atg} 7$. The form II of MAP LC3, named LC3 II, is involved in autophagosome membrane expansion and fusion events. ${ }^{17-21}$

In a previous work carried out at our labs, ${ }^{22}$ the autophagic activity of neurons and astrocytes from sheep brain under starving conditions was evaluated. The results showed that astrocytes are characterized by a higher upregulation of LC3 II immunoreactivity than neurons, where the LC3 II immunoreactivity was very weak. Therefore, it can be assumed that astrocytes show a higher capability than neurons to cope with stress and exhibit a stronger autophagic response.

In the present investigation, LC3 II expression over time has been evaluated in an aging neural model consisting in primary fetal sheep neurons and astrocytes. It is known that autophagy may differ in neurons and non-neuronal cells. ${ }^{23,24}$ So, in this investigation the possible differences in LC3 II immunoreactivity between astrocytes and neurons in primary cultures from fetal sheep brain have been examined during aging conditions. This approach could better clarify the role of astrocytes in the protection of neurons in brain aging. 


\section{Materials and Methods}

\section{Sample collection}

Twelve 40-day-old fetuses were obtained from sheep slaughtered in local public abattoirs for human nutrition when accidentally pregnant, so fetuses underwent immediate death. Consequently, neither were animals killed nor underwent any suffering for the present research. The period of gestation was established by measuring fetal crown-rump length, following the tables reported in the literature. ${ }^{25}$ Moreover, gestational age has been chosen as suitable to obtain viable neurons and astrocytes from sheep brain. ${ }^{26}$ Within one hour from fetus collection and under sterile conditions, the skull was opened, the brain visualized and the frontal cortex isolated and fragmented. Blocks were suspended in ice-cold cell freezing medium composed of Dulbecco's Modified Eagle's Medium (DMEM) with $1 \%$ HEPES (pH 7.4), 10\% fetal calf serum, and $10 \%$ dimethylsulfoxide (DMSO), following the cryopreservation method reported for bovine neural tissue. ${ }^{27}$ Cryotubes were slowly frozen to $-80^{\circ} \mathrm{C}$ and transferred to liquid nitrogen after $24 \mathrm{~h}$.

\section{Cell culture}

The procedure to obtain neural primary cultures was the same previously described ${ }^{28}$ and the most suitable period to grow viable neurons and astrocytes is around day 40 of sheep gestation. ${ }^{29}$

Frozen tissue blocks were rapidly thawed in water bath at $39^{\circ} \mathrm{C}$ and minced in smaller fragments under sterile conditions. A papain dissociation kit (Worthington Biochemical, Lakewood, NJ, USA) was used to dissociate cells. Cells were then suspended in basal medium consisting of a 1:1 mixture of DMEM and Ham's F12, supplemented with penicillin $(30 \mathrm{mg} / \mathrm{L})$, streptomycin $(50 \mathrm{mg} / \mathrm{L})$, sodium bicarbonate $(2.4 \mathrm{~g} / \mathrm{L})$, insulin $(10 \mu \mathrm{g} / \mathrm{mL})$, transferrin $(10$ $\mu \mathrm{g} / \mathrm{mL})$, sodium selenite $\left(10^{-8} \mathrm{M}\right)$ and $10 \%$ fetal calf serum. Cells were incubated at $39^{\circ} \mathrm{C}$ in a $5 \% \mathrm{CO}_{2}$ humidified atmosphere. The temperature of $39^{\circ} \mathrm{C}$ was chosen as it is the basal temperature in ovine species. Cells were plated at the rate of $5 \times 10^{5}$ on glass coverslips previously coated with poly-L- lysine (Sigma-Aldrich, St. Louis, MO, USA). Cells were cultured for 10, 20 and 30 days.

\section{Cell characterization}

One monolayer per brain, at 10,20 and 30 days of culture, was used to characterize cells by double immunofluorescence. The primary cultures were fixed with $4 \%$ paraformaldehyde at room temperature for $20 \mathrm{~min}$. After fixation, cells were washed with PBS, then permeabilized with $0.1 \%$ Triton X-100 for $10 \mathrm{~min}$, treated with $5 \%$ BSA buffer for $30 \mathrm{~min}$ to block endogenous nonspecific sites and incubated overnight with mouse monoclonal anti-III $\beta$-tubulin ${ }^{30}$ and rabbit polyclonal anti-glial fibrillary acidic protein (GFAP) antibodies, ${ }^{31}$ widelyrecognized markers of neuronal and glial cells respectively, diluted 1:200. Then monolayers were incubated for $1 \mathrm{~h}$ at $37^{\circ} \mathrm{C}$ with anti-mouse TRITC and anti-rabbit FITC conjugated antibodies diluted $1: 100 .^{32}$ All antibodies were from Sigma-Aldrich. One additional monolayer per brain was used as negative control by substituting the primary antibody with non-immune mouse and rabbit sera.

Stained and unstained cells were counted under confocal microscope at $40 \mathrm{X}$ magnification in random squared ROI (Region of Interest) from 4 different slides. Each ROI had a side of $387 \mu \mathrm{m}$. A minimum of 200 cells per field was counted per each time and the number was expressed in percentage. The counting was repeated by three different researchers to evaluate possible inter-observer differences which were lower than $2 \%$.

\section{Aging protocol}

Cells were cultured for 10,20 or 30 days with the medium changed every 3 days. This protocol was aimed at analyzing timedependent changes. Cultured cells grown on glass coverslips were fixed with $2 \%$ formaldehyde $0.2 \%$ glutharaldehyde at room temperature for $15 \mathrm{~min}$, washed three times and then treated with the marker of senescence $\beta$-galactosidase (Senescence $\beta$ galactosidase staining kit; Cell Signaling Technol., Danvers, MA, USA), pH 6 for 10 $\mathrm{h}$ at $37^{\circ} \mathrm{C}$ in the dark. After rinsing, cells were viewed under a Leica Leitz DM IL bright field microscope.

\section{LC3 II immunoreactivity}

In order to detect LC3 II immunoreactivity in neurons and astrocytes at 10, 20 and 30 days of culture, double immunofluorescence was performed using LC3 antibody together with cell type markers. In details, primary cultures were fixed with $4 \%$ paraformaldehyde at room temperature for $20 \mathrm{~min}$. After fixation, cells were washed with PBS, then permeabilized with $0.1 \%$ Triton X-100 for $10 \mathrm{~min}$, treated with 5\% BSA buffer for $30 \mathrm{~min}$ to block endogenous nonspecific sites and incubated overnight with one of the following monoclonal primary antibodies: anti-GFAP diluted 1:500, and anti-III $\beta$-tubulin, diluted 1:200. In addition, a polyclonal anti-LC3 II antibody, diluted 1:100 was used..$^{33}$ Cells were then incubated with a mixture of two secondary antibodies anti-rabbit TRITC, diluted 1:100, and anti-mouse FITC, diluted 1:100. All antibodies were from Sigma. All samples underwent blue nuclear counterstaining for fluorescence microscopy with Hoechst no. 33258 (Sigma-Aldrich). Finally, labeled cultures were mounted with FlourSaveTM Reagent (Calbiochem, San Diego, CA, USA). Cultures were observed and photographed using a Leica TCS confocal microscope with excitation and emission filters 488 and 527 for FITC, 543 and 587 for TRITC, and 365 and 448 for Hoechst blue no. 33258.

\section{Imaging and statistical analyses}

Microscopic pictures were taken of confluent and non-confluent monolayers, each including more than 50 cells. In order to quantify the cytochemical and immunofluorescence procedures, pictures were digitally captured and converted to bitmap format. Then, they underwent the validated computer software Scion Image (Scion Corporation, Frederick, MD, USA) to analyze difference in optical density. In details, after calibration, a square from the toolbox was employed to select an area with the cells to be analyzed. Values of optical density in the range of $0-255$ were expressed in percentage. Cell characterization was carried out by means of Image J $1.42 q$ software (Wayne Rasband, National Institutes of Health, USA). Observations were repeated in different times and by

Table 1. Cytoplasmic (C) and nuclear (N) localization of LC3 puncta related to cell types at different times.

\begin{tabular}{|c|c|c|c|c|c|c|c|}
\hline & \multirow[b]{2}{*}{ Localization } & \multicolumn{2}{|c|}{10 days } & \multicolumn{2}{|c|}{20 days } & \multicolumn{2}{|c|}{30 days } \\
\hline & & Isolated cells & Confluent cells & Isolated cells & Confluent cells & Isolated cells & Confluent cells \\
\hline \multirow[t]{2}{*}{ Neurons } & $\mathrm{C}$ & 0 & +/++ & $0 /+$ & ++ & + & \multirow[t]{2}{*}{+++} \\
\hline & $\mathrm{N}$ & + & +++ & + & +++ & + & \\
\hline \multirow[t]{2}{*}{ Astrocytes } & $\mathrm{C}$ & $0 /+$ & + & ++ & ++ & + & +++ \\
\hline & $\mathrm{N}$ & + & +++ & + & ++ & + & ++ \\
\hline
\end{tabular}


different observers to evaluate intra- and inter-variability that was lower than $2 \%$. All data were expressed as means $\pm \mathrm{SD}$ and were tested by the one-way analysis of variance Kruskal-Wallis test ( $R$ Software). A probability of 0.05 or less was considered as being significant. In order to verify possible differences in LC3 II immunofluorescence depending on the intracellular localization, pictures were observed by three independent observers, whose evaluations are summarized in Table 1.

\section{Results}

Primary cell cultures were viable and contained different neural cell types. Two cell populations were indeed present: i) III $\beta$-tubulin immunoreactive neurons; ii) GFAP-immunoreactive astrocytes.

Cell characterization revealed that at 10 days of culture about $60 \%$ of cells could be identified as neurons, whereas the remaining cells were astrocytes. At 20 days of culture the two cell populations were equivalent in percentage with a slight increase in astrocyte number in comparison with neurons. Finally, at 30 days of culture about $70 \%$ were astrocytes and the remaining were referred as neurons (Figure 1).

Neurons were mostly bipolar (about $90 \%$ ) displaying small and round cell bodies with thin extensions that tended to have contacts with those of the contiguous cells, whereas glial cells had the typical features of astrocytes, showing pleomorphic shape and a large flat cell body with long cytoplasmic processes forming a star-shaped network. $\beta$ galactosidase activity increased with time. It was indeed weak after 10 days of culture to become very marked after 20 days remaining high up to 30 days, when almost all cells were strongly positive (Figure 2).

The antibody against the marker of autophagy LC3 II revealed immunofluorescent puncta distributed in the cytoplasm and nuclei of both neurons and astrocytes (Figure 3). The optical density showed that LC3 II immunoreactivity in neurons progressively increased with time. Indeed, when expressed as percentage of its maximum value, it was $30 \%$ at 10 days to become $60 \%$ at 20 days and reach $100 \%$ at 30 days of culture. A similar pattern was observed in astrocytes, where at 10 days the optical density for LC3 II immunoreactivity was $45 \%$, at 20 days reached $65 \%$ and at 30 days rose up to $100 \%$ (Figure 4). Differences were observed on the basis of the cell confluence degree. Clustered cells of both cell types showed a higher LC3 II signal than non-confluent ones, after all time lapses. In addition, both cell types, when clustered, displayed a more marked LC3 II signal in
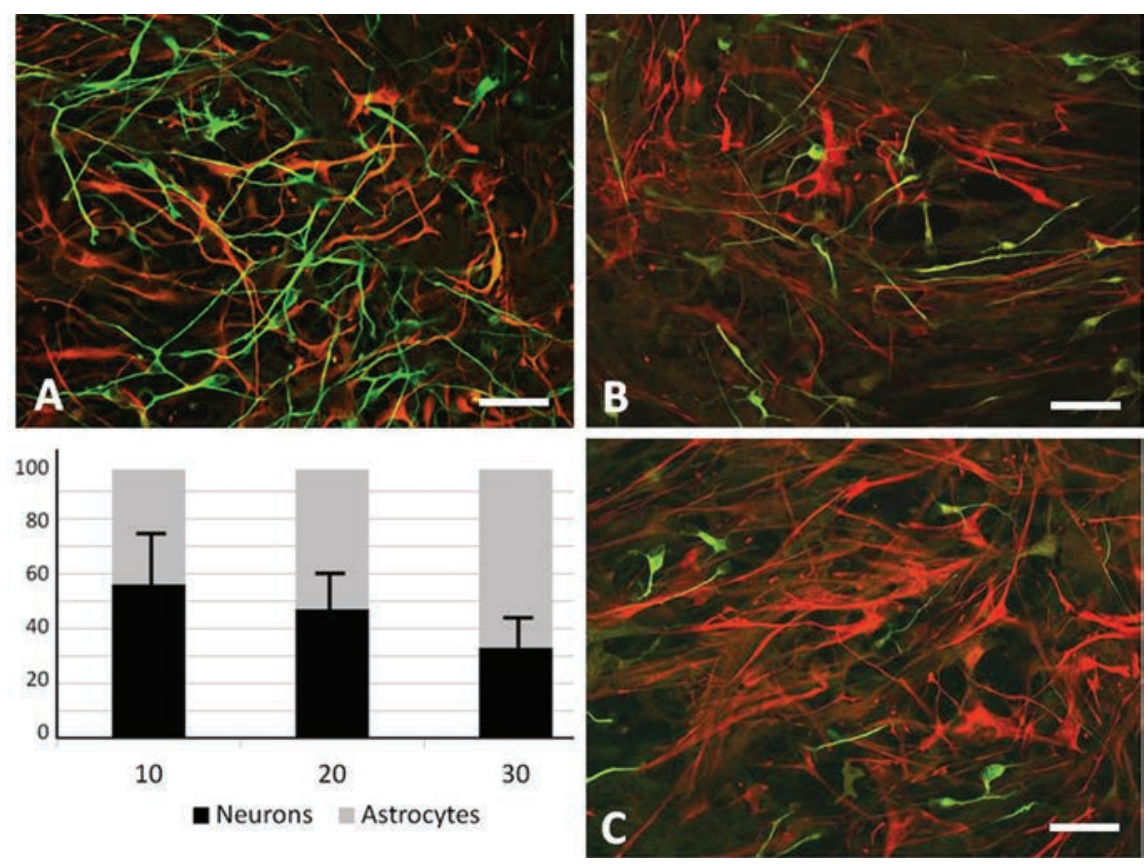

Figure 1. Cell populations at 10, 20, and 30 days (A,B and $C$, respectively). Neurons are green labeled with anti-III $\beta$-tubulin antibody, astrocytes are red labeled with anti-GFAP antibody. Double immunofluorescence. The diagram shows the variations in percentage of neurons and astrocytes over time. Scale bars: $80 \mu \mathrm{m}$.
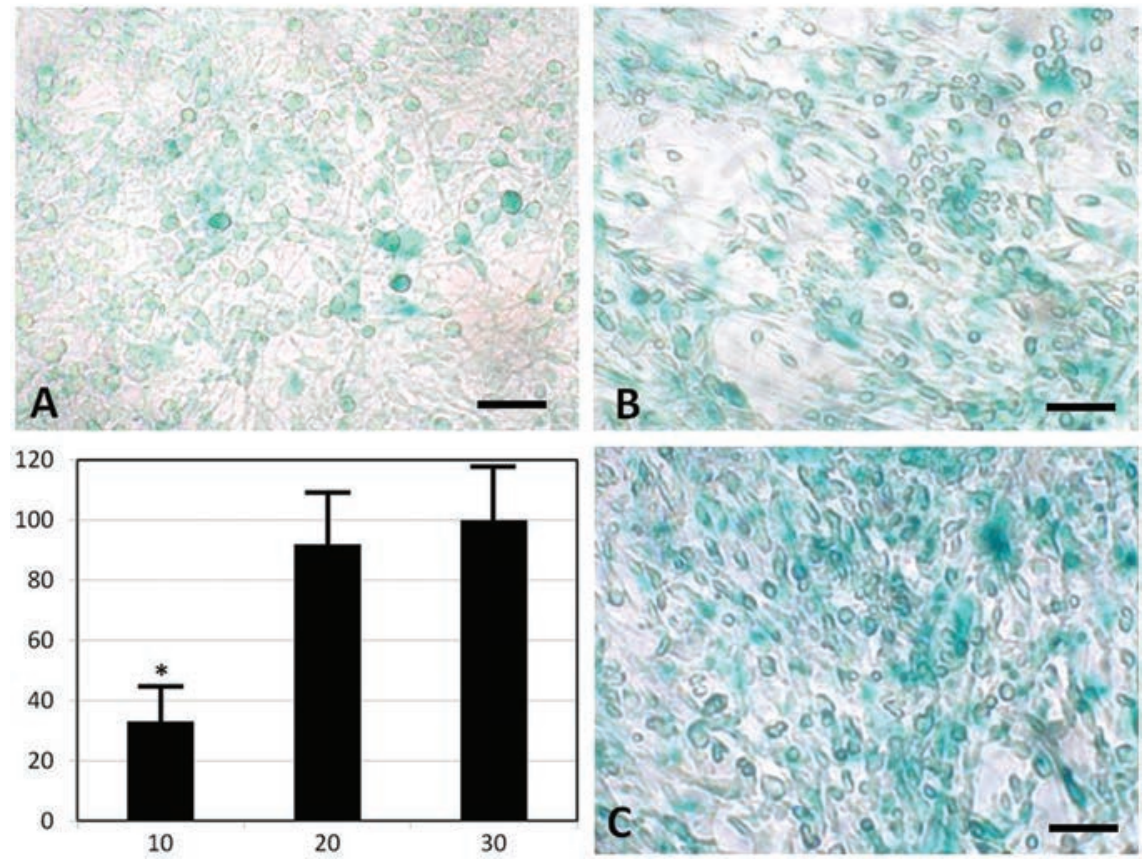

Figure 2. Cell cultures at 10, 20, and 30 days (A,B and C, respectively). The marker of senescence $\beta$-galactosidase increases after 20 and 30 days of culture. Optical density is expressed as percentage of its maximum value, i.e. 30 days of culture. *Significant difference between 10 and 20 days and between 10 and 30 days. Scale bars: $80 \mu \mathrm{m}$. 
nuclei than cytoplasm at 10 days, whereas the opposite was detected at 30 days with an intermediate pattern at 20 days. When isolated, LC3 II signal was always detected intracellular localization, regardless of the cell type and time (Table 1).

\section{Discussion}

In this study, the well-known marker of autophagy LC3 II was quantified in both neurons and astrocytes from 40-day sheep weakly with no significant differences in

embryos. The sheep was chosen as an experimental model for two reasons. The former is that sheep fetuses allow a rapid collection of considerable amounts of brain tissue in comparison to laboratory animals. ${ }^{26,28,29}$ The latter is the fact that sheep is susceptible to neurodegenerative diseases such as Scrapie and Maedi-Visna diseases $^{34,35}$ and in neurodegenerative disorders an outstanding role is played by oxidative stress, which are implicated in the mechanisms of brain senescence. ${ }^{36,37}$

The setup of primary cultures allowed to obtain two cell types, i.e., III $\beta$-tubulinimmunopositive neurons and GFAP-
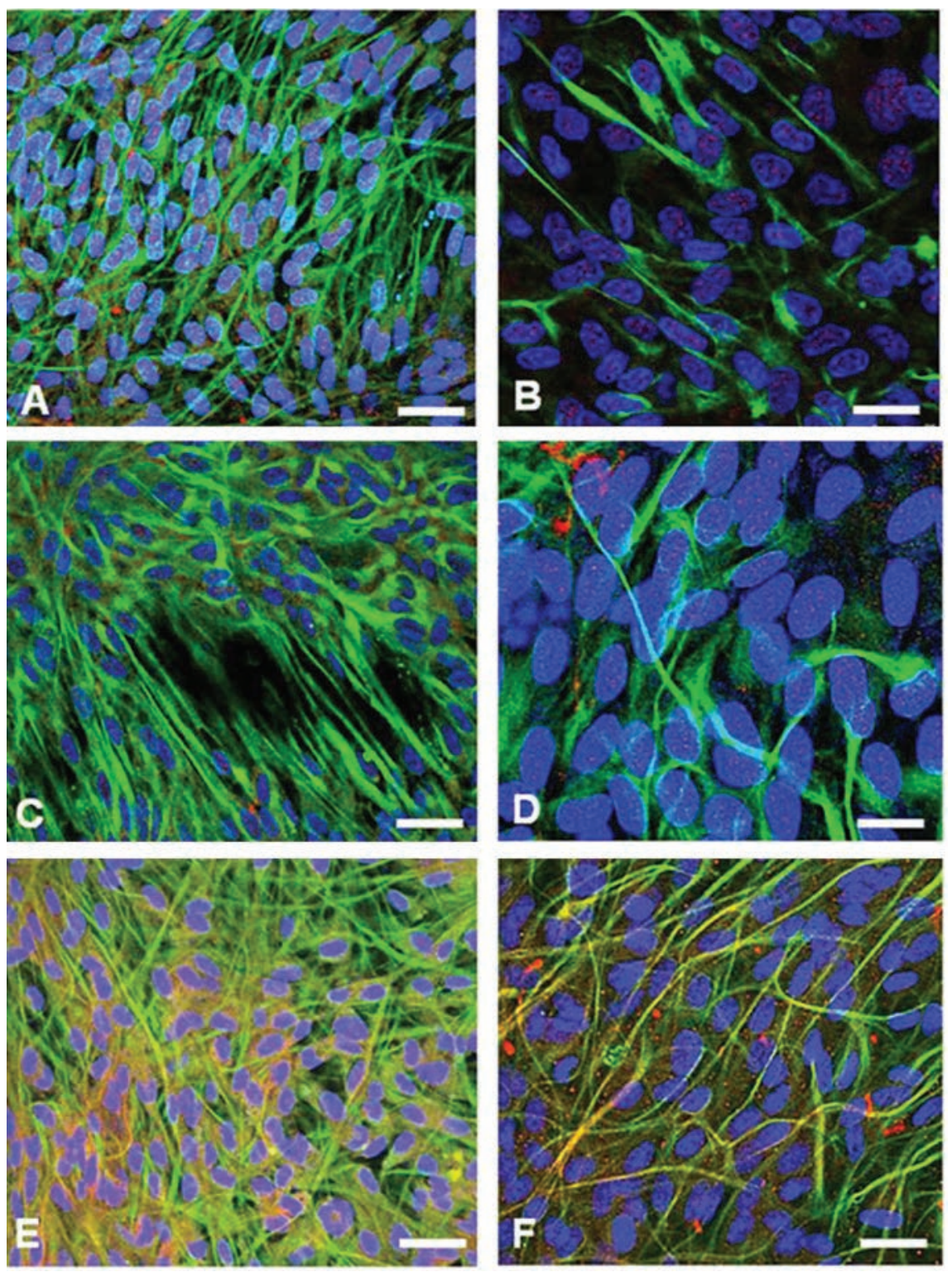

Figure 3. LC3 II immunoreactivity in neurons $(A, C, E)$ and astrocytes $(B, D, F)$ at $10(A, B)$, 20 (C,D), and 30 days (E,F) of culture. LC3 II signal (red puncta) is more marked in nuclei than cytoplasm at $\mathbf{1 0}$ days, whereas the opposite was detected at 30 days with an intermediate pattern at 20 days. Neuronal cytoplasm is green stained with anti-III $\beta$ tubulin, astrocytic cytoplasm is green stained with anti-GFAP. Nuclei are counterstained with Hoechst blue dye. Scale bars: A,C,E,F) $60 \mu \mathrm{m}$; B,D) $20 \mu \mathrm{m}$. immunopositive astrocytes. At 10 days of culture, the cell population was mainly constituted of neurons, whereas at the end of the examined period ( 30 days of culture) astrocytes were prevalent on neurons. This is in accordance with Richard et al., ${ }^{26}$ whose work showed an increase in the number of astrocytes with time. In our protocol, $\beta$ galactosidase activity increased with time, so it may be seen as a reliable model of cell senescence in agreement with what reported by Dimri et al. ${ }^{11}$, who affirmed that the marker $\beta$-galactosidase was expressed by senescent fibroblasts and keratinocytes, and Tsuchihashi et al. ${ }^{38}$, who noted an increase in both $\beta$-galactosidase activity and LC3 II expression occurring in auditory senescent cells exposed to $\mathrm{H}_{2} \mathrm{O}_{2}$ in a concentrationdependent manner. The gradual increase in LC3 II immunoreactivity detected in both the cell types during time clearly indicates that senescence induces a significant strengthening of autophagic processes. One of the mechanisms at the base of the relationship between senescence and autophagy could be the increase in the expression of the chaperone protein BAG3, a molecule expressed in autophagic processes that has been observed during aging. ${ }^{39}$

In our opinion, it is of interest to note that clustered cells display a different pattern of LC3 II expression in comparison to isolated cells and this occurs in both cell populations after the same period of time (Table 1). Indeed, LC3 II immunoreactivity is higher in clustered cells and this may be due to the fact that cell-cell contact would represent a second stress in addition to aging itself. It is reported that contact-inhibited cells show an evident $\beta$-galactosidase staining, so it can be seen not only as a

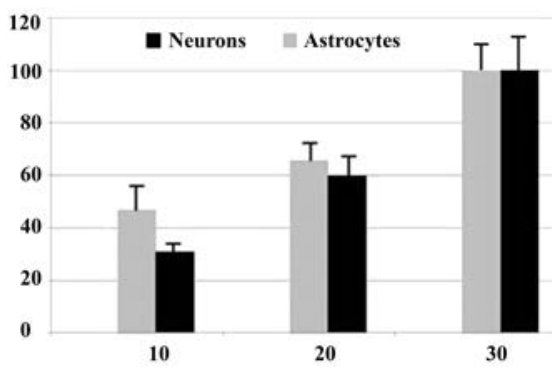

Figure 4. The optical density reveals that LC3 II expression increases with time in neurons and astrocytes. Values are expressed as percentage of their maximum value for both confluent cell types, i.e., 30 days of culture. 
marker of senescence but also of contact inhibition. ${ }^{40,41}$ Such two conditions, aging and contact inhibition as well as serum deprivation, are associated with lysosomal activation. $^{42,43}$ Clustered neurons and astrocytes displayed a reduction in LC3 II signal in nuclei, and a corresponding strengthening in the cytoplasm with time. This may be due to the need of aged cells to remove damaged cytoplasmic components through autophagic processes. ${ }^{44,45}$ Such variation in LC3 II localization could be caused by migration from the nucleus to cytoplasm as well as a possible de novo intracytoplasmic production.

When isolated, LC3 signal was always detected weakly with no significant differences in intracellular localization, regardless of the cell type and time. The observation that cells express higher amounts of LC3 II when clustered rather than isolated during aging, suggests that contact inhibition might enhance autophagic processes. The present work based on sheep neural cells in vitro may provide a helpful tool in the studies on aging processes in which autophagy plays a remarkable role.

\section{References}

1. Campisi J, d'Adda di Fagagna F. Cellular senescence: when bad things happen to good cells. Nat Rev Mol Cell Biol 2007;8:729-40.

2. Le Bel CP, Bondy SC. Oxidative damage and cerebral aging. Prog Neurobiol 1992;38:601-9.

3. Haigis MC, Yankner BA. The aging stress response. Mol Cell 2010;40:33344.

4. Bassett CN, Montine TJ. Lipoproteins and lipid peroxidation in Alzheimer's disease. J Nutr Health Aging 2003; 7:249.

5. Butterfield DA, Sultana R. Redox proteomics identification of oxidatively modified brain proteins in Alzheimer's disease and mild cognitive impairment: insights into the progression of this dementing disorder. J Alzheimers Dis 2007;12:61-72.

6. Hamilton ML, Van Remmen H, Drake JA, Yang H, Guo ZM, Kewitt K, et al. Does oxidative damage to DNA increase with age? Proc Natl Acad Sci USA 2001;98:10469-74.

7. Ben-Porath I, Weinberg RA. When cells get stressed: an integrative view of cellular senescence. J Clin Invest 2004; 113:8-13.

8. Wang C, Jurk D, Maddick M, Nelson G, Martin-Ruiz C, von Zglinicki T. DNA damage response and cellular senescence in tissues of aging mice. Aging
Cell 2009;8:311-23.

9. Andersen JK. Oxidative stress in neurodegeneration: cause or consequence? Nat Med 2004;10:18-25.

10. Sayre LM, Perry G, Smith MA. Oxidative stress and neurotoxicity. Chem Res Toxicol 2008;21:172-188.

11. Dimri GP, Lee X, Basile G, Acosta M, Scott G, Roskelley C, et al. A biomarker that identifies senescent human cells in culture and in aging skin in vivo. Proc Natl Acad Sci USA 1995;92:93637.

12. Lepore G, Zedda M, Mura E, Giua S, Dedola GL, Farina V. Brain aging and testosterone-induced neuroprotection: studies on cultured sheep cortical neurons. Neuro Endocrinol Lett 2013; 34:395-401.

13. Kondapi AK, Mulpuri N, Mandraju RK, Sasikaran B, Subba Rao K. Analysis of age dependent changes of Topoisomerase II alpha and beta in rat brain. Int J Dev Neurosci 2004;22:19-30.

14. Mizushima N, Levine B, Cuervo AM, Klionsky DJ. Autophagy fights disease through cellular self-digestion. Nature 2008;45:1069-75.

15. Levine B, Klionsky DJ. Development by self-digestion: Molecular mechanisms and biological functions of autophagy. Dev Cell 2004; 6:463-77.

16. Kihara A, Kabeya Y, Ohsumi Y, Yoshimori T. Beclin-phosphatidylinositol 3-kinase complex functions at the trans-Golgi network. EMBO Rep 2001; 2:330-5.

17. Iwata A, Riley BE, Johnston JA, Kopito RR. HDAC6 and microtubules are required for autophagic degradation of aggregated huntingtin. J Biol Chem 2005;280:40282-92.

18. Behrends C, Sowa ME, Gygi SP, Harper JW. Network organization of the human autophagy system. Nature 2010;466:68-76.

19. Polson HE, de Lartigue J, Rigden DJ, Reedijk M, Urbé S, Clague MJ, et al. Mammalian Atg18 (WIPI2) localizes to omegasome-anchored phagophores and positively regulates LC3 lipidation. Autophagy 2010;6:506-22.

20. Riley BE, Kaiser SE, Shaler TA, Ng AC, Hara T, Hipp MS, et al. Ubiquitin accumulation in autophagy-deficient mice is dependent on the Nrf2-mediated stress response pathway: a potential role for protein aggregation in autophagic substrate selection. J Cell Biol 2010; 19:537-52.

21. Weidberg H, Shpilka T, Shvets E, Abada A, Shimron F, Elazar Z. LC3 and GATE-16 $\mathrm{N}$ termini mediate membrane fusion processes required for autophagosome biogenesis. Dev Cell
2011;20:444-54.

22. Mura E, Lepore G, Zedda M, Giua S, Farina V. Sheep primary astrocytes under starvation conditions express higher amount of LC3 II autophagy marker than neurons. Arch Ital Biol 2014;152:47-56.

23. Yue Z, Friedman L, Komatsu M, Tanaka K. The cellular pathways of neuronal autophagy and their implication in neurodegenerative diseases. Biochim Biophys Acta 2009;1793: 1496-1507.

24. Di Malta C, Fryer JD, Settembre C, Ballabio A. Autophagy in astrocytes: A novel culprit in lysosomal storage disorders. Autophagy 2012;8:1871-2.

25. McGeady TA, Quinn PJ, FitzPatrick ES, Ryan MT. Veterinary embryology. Oxford, UK: Blackwell Publishing, 2006.

26. Richard O, Duittoz AH, Tobias KH. Early, middle, and late stages of neural cells from ovine embryo in primary cultures. Neurosci Res 1998;1:61-8.

27. Hashimoto A, Onodera T, Ikeda H, Kitani H. Isolation and characterisation of fetal bovine brain cells in primary culture. Res Vet Sci 2000;69:39-46.

28. Lepore G, Gadau S, Mura A, Zedda M, Farina V. Aromatase immunoreactivity in fetal ovine neuronal cell cultures exposed to oxidative injury. Eur J Histochem 2009; 53:233-8.

29. Kay GW, Oswald MJ, Palmer DN. The development and characterisation of complex ovine neuron cultures from fresh and frozen foetal neurons. J Neurosci Methods 2006;155:98-108.

30. Banerjee A, Roach MC, Trcka P, Ludueña RF. Increased microtubule assembly in bovine brain tubulin lacking the type III isotype of beta-tubulin. J Biol Chem 1990;265:1794-9.

31. Jacquier A, Bellouze S, Blanchard S, Bohl D, Haase G. Astrocytic protection of spinal motor neurons but not cortical neurons against loss of Als2/alsin function. Hum Mol Genet 2009;18:2127-39.

32. Thore CR, Nam MJ, Busija DW. Immunofluorescent localization of constitutive and inducible prostaglandin $\mathrm{H}$ synthase in ovine astroglia. J Comp Neurol 1996;367:1-9.

33. Lana $Y$, Wangb G, Songa D, Hea W, Zhanga D, Huanga $\mathrm{H}$, et al. Role of autophagy in cellular response to infection with Orf virus Jilin isolate. Vet Microbiol 2016;193:22-7.

34. Strijbos PJ, Zamani MR, Rothwell NJ, Arbuthnott G, Harkiss G. Neurotoxic mechanisms of transactivating protein Tat of Maedi-Visna virus. Neurosci Lett 1995;197:215-8.

35. Starling I, Wright A, Arbuthnott G, 
Harkiss G. Acute in vivo neurotoxicity of peptides from Maedi Visna virus transactivating protein Tat. Brain Res 1999;830:285-91.

36. Salminen A, Ojala J, Kaarniranta K, Haapasalo A, Hiltunen M, Soininen $\mathrm{H}$. Astrocytes in the aging brain express characteristics of senescence-associated secretory phenotype. Eur J Neurosci 2011;34:3-11.

37. Sykora P, Wilson DM 3rd, Bohr VA. Base excision repair in the mammalian brain: Implication for age related neurodegeneration. Mech Ageing Dev 2013;134:440-8.

38. Tsuchihashi NA, Hayashi K, Dan K, Goto F, Nomura Y, Fujioka M, et al. Autophagy through 4EBP1 and AMPK regulates oxidative stress-induced premature senescence in auditory cells. Oncotarget 2015;6:3644-55.

39. Carroll B, Hewitt G, Korolchuk VI. Autophagy and ageing: implications for age-related neurodegenerative diseases. Essays Biochem 2013;55:119-31.

40. Leontieva OV, Blagosklonny MV. Gerosupression in confluent cells. Aging 2014;12:1010-8.

41. Leontieva OV, Demidenko ZN, Blagosklonny MV. Contact inhibition and high cell density deactivate the mammalian target of rapamycin pathway, thus suppressing the senescence program. Proc Natl Acad Sci USA 2014;111:8832-7.

42. Knecht E, Hernández-Yago J, Grisolía
S. Regulation of lysosomal autophagy in transformed and non-transformed mouse fibroblasts under several growth conditions. Exp Cell Res 1984;154:22432 .

43. Blagosklonny MV. Hypoxia, MTOR and autophagy: converging on senescence or quiescence. Autophagy 2013; 9:260-2.

44. Drake KR, Kang M, Kenworthy AK. Nucleocytoplasmic distribution and dynamics of the autophagosome marker EGFP-LC3. PLoS One 2010;5:e9806.

45. Huang R, Xu Y, Wan W, Shou X, Qian J, You Z, et al. Deacetylation of nuclear LC3 drives autophagy initiation under starvation. Mol Cell 2015;57:456-66. 